\title{
AMPEROMETRIC METHOD FOR TRACE LEVEL DETERMINATION OF THE FUNGICIDE, THIRAM
}

\author{
NAMAL PRIYANTHA* and SISIRA WELIWEGAMAGE \\ Department of Chemistry, University of Peradeniya, Peradeniya.
}

(Received: 03 January 2003 ; accepted: 16 August 2004)

\begin{abstract}
Thiram, a dithiocarbamate fungicide, is electrochemically active on glassy carbon electrodes in an aqueous medium. An amperometric method developed under optimized conditions produces smooth and reproducible responses, yielding linear calibration curves with a minimum detection limit of $1.0 \times 10^{-8} \mathrm{M}$, based on the signal-to-noise ratio (S/N) of 3. Application of this methodology for the determination of Thiram in water leachates, collected at various time intervals from a laboratory prepared soil bed, results in reliable results. Additionally, the amount of Thiram in an agricultural bean seed sample is well quantified using this methodology, thus demonstrating the applicability of the proposed amperometric method in real sample analysis. NMR and UV-visible spectroscopic methods confirm the presence of Thiram in the seed sample.
\end{abstract}

Key Words: amperometry, cyclic voltammetry, dithiocarbamate fungicide.

\section{INTRODUCTION}

Modern agriculture depends largely on pesticides for crop protection. Nevertheless, pesticides have caused severe problems on both the physical environment and on the biosphere. Bioaccumulation, carcinogenity and mutagenic effects, which are usually associated with pesticides, have caused threatening problems on living forms. ${ }^{1,2}$ As pesticides show hazardous effects even at very low concentrations, continuous monitoring of the levels of pesticides and their residues in the environment is of great importance.

Thiram is a broad-spectrum dithiocarbamate fungicide with a non-systemic action. ${ }^{3}$ It is used against a large number of fungal pathogens, ${ }^{4}$ and as a seed and soil treatment agent. ${ }^{5,6}$ Consequently, there is a possibility of pollution of soil and water in agricultural areas, where Thiram is used. It is also reported that some fruits and vegetables contain appreciable amounts of Thiram and other dithiocarbamates. ${ }^{7,8}$ As Thiram is fairly persistent in soil, it would give rise to long-term pollution problems.
Chemical conversion to dimethylamine, followed by titration with a standard hydrochloric acid solution is the accepted classical method for the determination of Thiram. ${ }^{9}$ In spectrophotometric determination of Thiram, the sample is refluxed with a dilute mineral acid, and the carbon disulphide evolved is reacted to form the yellow cupric salt of N-N'bis(2hydroxyethyl)dithiocarbamic acid, which is monitored colorimetrically. ${ }^{10}$ The amount of carbon disulfide released during this degradation can also be quantified by gas chromatography. ${ }^{11}$ Among recent developments for the detection of Thiram; reversed-phase liquid chromatography with UV, mass spectrometric, amperometric or coulometric detection; ${ }^{12,13}$ ultrasonic assisted, mechanical extraction, followed by flow injection FTIR determination; ${ }^{14}$ capillary electrophoresis by direct UV absorbance detection at $254 \mathrm{~nm} ;{ }^{15}$ and enzyme immunoassay technology; ${ }^{16}$ have been reported.

There are many drawbacks associated with the methods reported above. Although they are reliable and sensitive, economic factors and environmental nonfriendliness are of great concern. Furthermore, analyses that involve an additional chemical step, such as degradation, are cumbersome. Therefore, a search for an alternative analytical methodology that addresses the key issues stated above, for the detection of pesticides would be highly attractive. Electroanalytical methods offer many desirable features, and hence they have become a logical alternative in this regard. Although the use of such methods in the field of pesticide analysis is still in the early stages, there is a growing interest to develop electroanalytical methods owing to their adherent properties. ${ }^{17-19}$

In recent years, determination of Thiram by voltammetric methods, including polarography has been successfully accomplished in nonaqueous

" Corresponding author 
media within a linear range of detection down to $1 \times 10^{-6}$ M. ${ }^{17}$ The limit of detection has been improved by an order of magnitude with metallophthalocyanine catalytic electrodes ${ }^{18}$ or microelectrodes. ${ }^{19}$ However, uses of aqueous medium, interferent problems and further decrease in lower detection limits have not been fully addressed according to these reports.

The study reported here deals with the determination of Thiram in aqueous medium using amperometric methods. Use of aqueous medium would be highly desirable to design environmentally friendly and economical detection methods. Further, decrease in the limit of detection and interferent problems are successfully addressed by careful optimization of experimental conditions. Consequently, the proposed method is applied for accurate determination of Thiram in real samples.

\section{METHODS AND MATERIALS}

Materials: A commercial sample of Thiram $\left[\left(\mathrm{H}_{3} \mathrm{C}\right)_{2} \mathrm{NCSSCN}\left(\mathrm{CH}_{3}\right)_{2}\right](80 \% \mathrm{w} / \mathrm{w})$ was provided by Haychem (Ceylon) Ltd., Sri Lanka, which was used throughout the study without any purification. All the electrolytes, $\mathrm{KH}_{2} \mathrm{PO}_{4}, \mathrm{KCl}$, $\mathrm{LiCl}, \mathrm{NaCl}, \mathrm{CdCl}_{2} \mathrm{Na}_{2} \mathrm{SO}_{4}, \mathrm{Na}_{2} \mathrm{CO}_{3}, \mathrm{Na}_{2} \mathrm{~B}_{4} \mathrm{O}_{7}$ and $\mathrm{NaOH}$, were analytical grade, purchased from Aldrich Chemical Company, USA. All the electrolyte solutions and Thiram solutions were freshly prepared in distilled deionized water. The strength of all buffers was $0.1 \mathrm{M}$.

Instrumentation: A CV-1B cyclic voltammograph and an $\mathrm{X}-\mathrm{Y}$ recorder, both from Bioanalytical Systems, USA, were used for all cyclic voltammetric and amperometric experiments. The three-electrode cell consisted of a glassy carbon (GC) working electrode, a platinum counter electrode and a saturated calomel reference electrode (SCE). A 50- $\mathrm{cm}^{3}$ Pyrex glass beaker served as the electrochemical cell. All potentials were reported with respect to $\mathrm{SCE}$ at room temperature, and all experiments were conducted under $\mathrm{N}_{2}$ saturated conditions.

NMR spectra were obtained using a Varian Mercury $300 \mathrm{MHz}$ spectrometer, equipped with a $5.0 \mathrm{~mm}\left(5.0 \times 10^{-3} \mathrm{~m}\right)$ proton optimized probe. UV-Visible spectra were obtained using a Shimadzu 160 UV Visible recording spectrophotometer.
Cyclic Voltammetric Experiments: The initial cyclic voltammetric studies were carried out in aqueous solutions of $0.1 \mathrm{M} \mathrm{NaCl}, \mathrm{KCl}$ or $\mathrm{Na}_{2} \mathrm{SO}_{4}$ in order to check the electroactivity of Thiram. The variation of peak potential with solution $\mathrm{pH}$ was studied in buffered systems of $\mathrm{pH} 1,2,3,4$, $5,6,7,8,9,10$ and 11 .

Amperometric Experiments: More sensitive amperometric experiments were carried out at different potentials, which were determined from cyclic voltammetric studies, and at different $\mathrm{pHs}$. These responses were then investigated to determine the optimized conditions for the detection of Thiram.

Validation of the Method: Under the optimized conditions, several amperometric experiments were conducted using various known stock solutions in which concentration of Thiram varied from $5 \times 10^{-5} \mathrm{M}$ to $2.5 \times 10^{-7} \mathrm{M}$. The proportionality of amperometric current response to bulk concentration was then investigated.

Study of Interferences: Inorganic cations and anions, which are commonly found in natural waters, such as $\mathrm{Br}, \mathrm{Cl}^{-}, \mathrm{Co}^{2+}, \mathrm{Cu}^{2+}, \mathrm{Fe}^{3+}, \mathrm{HCO}_{3}^{-}$, I, $\mathrm{Mn}^{2+}, \mathrm{NO}_{3}^{-}, \mathrm{NO}_{2}^{-}, \mathrm{PO}_{4}{ }^{3-}, \mathrm{SO}_{4}^{2-}, \mathrm{S}^{2-}$ and $\mathrm{Zn}^{2+}$, were selected as inorganic interferents, while Benomyl (a fungicide), Captan (a fungicide), cystine, methylamine and phenol were tested as organic interferents. Amperometric studies were carried out for the standard solutions of interferents and Thiram at the same concentration. Three electrolyte media, $0.1 \mathrm{M} \mathrm{KCl}$ solution, buffer of $\mathrm{pH} 10$ and buffer of $\mathrm{pH} 1$, were used in this investigation. The ratio of the amperometric response of each interferent to that of Thiram was then determined.

Applications: A soil bed was prepared with a surface area of $0.184 \mathrm{~m}^{2}$ and $10 \mathrm{~cm}(0.1 \mathrm{~m})$ in depth in the laboratory. The soil in the bed was conditioned by regular addition of water. Then, the recommended dose for that size of area, $1.61 \mathrm{~g}$ of Thiram mixed with $1.8 \mathrm{dm}^{3}$ of water, was applied to the bed. The water leached out from the soil was collected at time intervals of $6,12,24,36$, 48,72 and 96 hours and tested amperometrically.

For the second type of application, an agricultural bean seed sample, suspected to be deliberately mixed with Thiram for preservation, was purchased from the local market. $500 \mathrm{~g}$ of 
seeds were washed several times with chloroform to dissolve any Thiram that had been mixed with the sample. The solvent was removed using a rotary vacuum evaporator. The dry residue obtained had a weight of $0.412 \mathrm{~g} .0 .109 \mathrm{~g}$ of it was dissolved in the $\mathrm{pH} 10$ borate buffer, and tested amperometrically. The mass of Thiram present in bean seeds, in $\mathrm{g} / \mathrm{kg}$, was then determined.

\section{Spectroscopic Evidence for the Presence of Thiram} in the Bean Seed Sample: The presence of Thiram in bean seeds was qualitatively tested with 300 $\mathrm{MHz}$ NMR spectra, taken separately for the commercial Thiram sample and for the residue obtained from the bean seeds extract. Similarly, both the standard solution of Thiram and the extract of the bean seeds sample, prepared in aqueous medium at $\mathrm{pH} 10$, were investigated with UV absorption measurements.

\section{RESULTS AND DISCUSSION}

Cyclic voltammetric experiments: According to cyclic voltammetric experiments of Thiram, conducted in $0.1 \mathrm{M} \mathrm{KCl}$ electrolyte at GC electrodes, it was found to be electroactive within the working potential range of the electrode (Figure 1). Among the major electrochemical peaks; two oxidations were at $+0.75 \mathrm{~V}$ (A) and $+0.21 \mathrm{~V}(\mathrm{~B})$, and two reductions at $+0.26 \mathrm{~V}(\mathrm{C})$ and $-0.47 \mathrm{~V}$ (D). The most efficient oxidation was found to be associated with the peak centered at $+0.75 \mathrm{~V}$. Consequently, this potential was selected for investigation of the possibility of using GC electrodes in the quantitative analysis of Thiram. Although the potentials of the other three peaks were closer to $0 \mathrm{~V}$, they appeared as weak responses. Therefore, the results would involve high uncertainties at low concentrations if such peaks were used in quantitative analysis.

The current of the peak at $+0.75 \mathrm{~V}$ was found to be concentration dependent between $9.1 \times 10^{-6} \mathrm{M}$ and $3.8 \times 10^{-5} \mathrm{M}$ Thiram (Figure 2), demonstrating the analytical utility of GC electrodes for Thiram. Additionally, the oxidation potential shows a gradual decrease with the increase in $\mathrm{pH}$ (Figure 3). Higher $\mathrm{pHs}$ would therefore be appropriate for the detection of Thiram, and many interfering reactions can also be minimized if Thiram is detected at lower potentials. However, no significant voltammetric features are apparent when the solution $\mathrm{pH}$ is increased beyond 10 , which is probably due to the decomposition of Thiram in basic medium..$^{20}$ It is therefore suggested that a $\mathrm{pH}$ of 10 be the best compromise for the detection of Thiram.

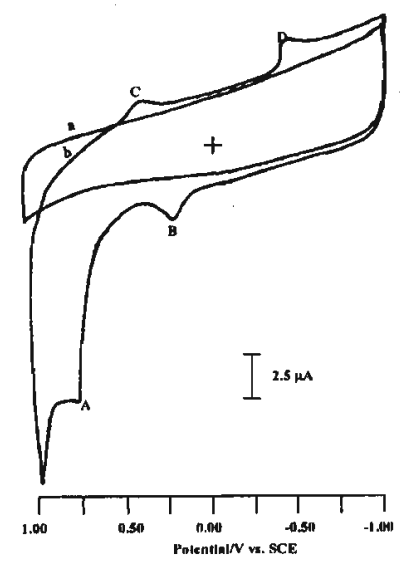

Figure 1: Cyclic voltammogram of Thiram in $0.1 \mathrm{M} \mathrm{KCl}$ at a scan rate of 50 $\mathrm{mV} \mathrm{s}^{-1}$ under $\mathrm{N}_{2}$ saturated. (a) supporting electrolyte only (b) $1.0 \times 10^{-4} \mathrm{M}$ Thiram.

Amperometric experiments: The amperometric studies of Thiram were initially performed in simple unbuffered systems, such as KCl. However, such conditions were unsatisfactory due to high noise, throughout the concentration range investigated from $2.0 \times 10^{-6} \mathrm{M}$ to $1.4 \times 10^{-5} \mathrm{M}$. This noise situation can be improved, especially at low concentrations; in phosphate, phthalate or borate buffered systems.

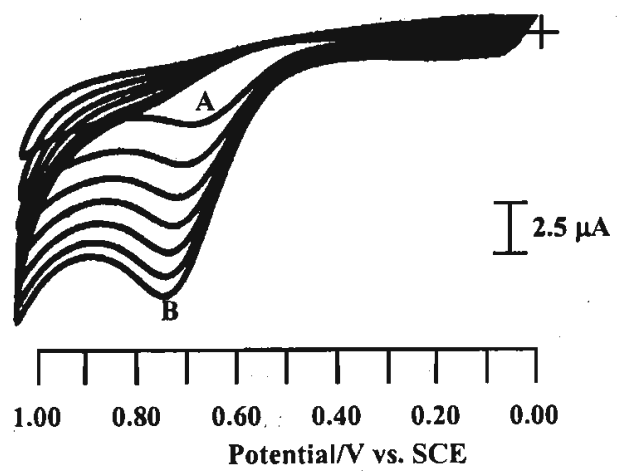

Figure 2: Effect of the concentration of Thiram on the main oxidation peak in $0.1 \mathrm{M} \mathrm{KCl}$ at a scan rate of $50 \mathrm{mV} \mathrm{s} \mathrm{m}^{-1}$ under $\mathrm{N}_{2}$ saturated. The concentration of Thiram associated with the lowest and the highest peak currents are $9.1 \times 10^{-6} \mathrm{M}$ and $3.8 \times 10^{-5} \mathrm{M}$. 
As the oxidation potential of Thiram varied with $\mathrm{pH}$, amperometric experiments were conducted at different $\mathrm{pHs}$ in the range of 1 to 11 , at their respective peak potentials, in an attempt to optimize the solution $\mathrm{pH}$ for Thiram detection (Figure 4).

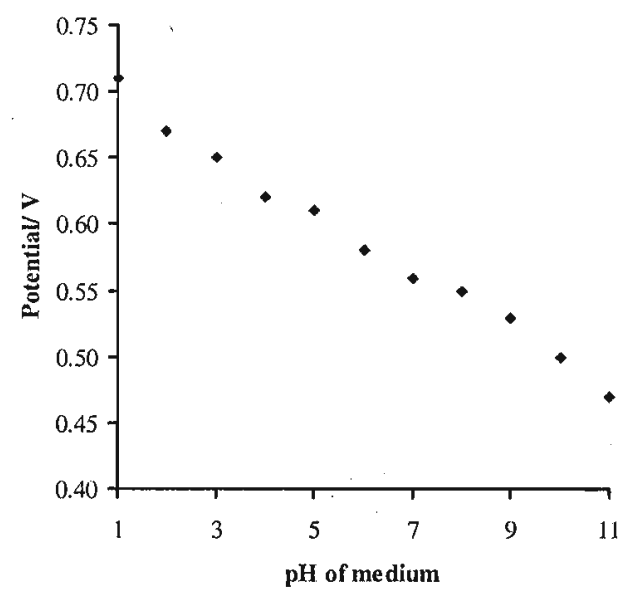

Figure 3: Effect of $\mathrm{pH}$ on the oxidation potentjal of Thinem $\left(1,0 \times 10^{-4} \mathrm{M}\right)$, as determined from cyclic voltammetric measurements at a scan rate of $50 \mathrm{mV} \mathrm{s}{ }^{-1}$ under $N_{2}$ saturated.

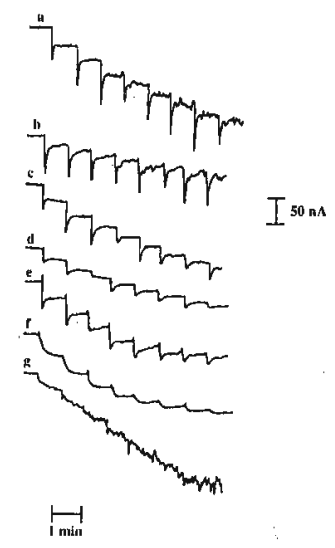

Figure 4: Nature of amperograms at different pHs at their respective peak potentials. (a) pH 1 ( $\mathrm{HCl} /$ $\mathrm{KCl}$ ), +0.71V (b) pH 3 (phthalate), $+0.65 \mathrm{~V}$, (c) pH 5 (phthalate), +0.62 $\mathrm{V}$, (d) pH 7 (phosphate), $+0.56 \mathrm{~V}$, (e) pH 9 (borate), +0.52V, (f) pH10 (borate), +0.50V, (g) pH 11 ( c a r b o a t e ), + $0.47 \mathrm{~V}$. Concentration increments were $0.1 \mu \mathrm{M}$ in each case.
The amperograms obtained in highly acidic $(\mathrm{pH}=1,3)$ and highly basic $(\mathrm{pH}=11)$ conditions are too noisy, and do not produce any useful information. Although amperograms at $\mathrm{pH}$ 5 and 7 are associated with less noise, their sensitivity is low. Thus, by careful investigation of the features of the amperograms in Figure 4, it is concluded that the $\mathrm{pH}$ of 10 , beyond which the analyte is unstable, is the best $\mathrm{pH}$ for amperometry. This observation is also supported by cyclic voltammetric findings where the oxidation potential is found to be lower at higher $\mathrm{pHs}$. At $\mathrm{pH}$ of 10, the potential of operation can be made as low as $+0.50 \mathrm{~V}$ for amperometric detection. Further buffers of $\mathrm{pH} 10$ prepared with borates and bicarbonates resulted in similar amperograms, indicating that amperometric response may not be dependent on the composition of the buffer.

The calibration curves obtained under optimized conditions $(\mathrm{pH}=10,+0.50 \mathrm{~V}$ ) produce a linear dvnamic range from $2.8 \times 1 \Omega^{-8} \mathrm{M}_{2}+\omega_{2}{ }_{2}, 0 \times 1 \mathrm{~N}_{\mathrm{N}}$ ${ }^{7} \mathrm{M}$ (Figure 5). According to the calibration curve, the sensitivity of detection (i.e., the slope of the graph) was determined to be $3.3 \times 10^{5} \mu \mathrm{A} \mathrm{M}^{-1}$. The minimum detection limit for Thiram, based on the signal-to-noise $(\mathrm{S} / \mathrm{N})$ ratio of 3 , was estimated to be $1.0 \times 10^{-8} \mathrm{M}\left(2.4 \mu \mathrm{g} \mathrm{dm}^{-3}\right)$ indicating that the amperometric method developed has the ability to detect Thiram at such low levels, which is a significant achievement. Additionally, amperometric responses obtained for solutions of known concentration resulted in an accuracy of $90 \%$, based on the calibration curve in Figure 5,

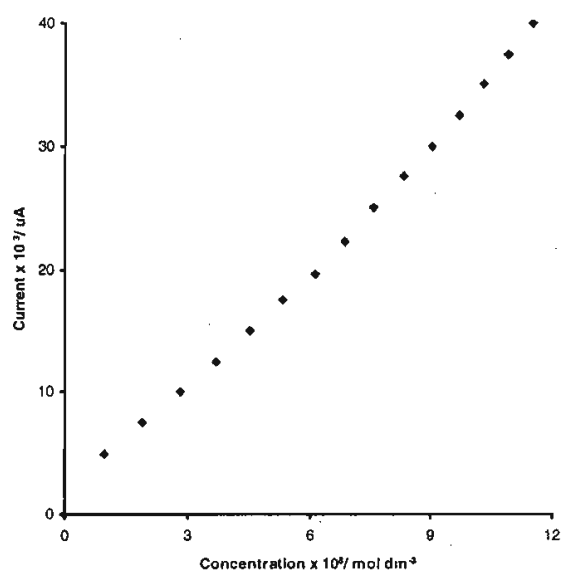

Figure 5: Amperometric calibration curve for the detection of Thiram, in $\mathrm{pH}$ 10 borate buffer $(0.1 \mathrm{M})$ at +0.50 $\mathrm{V}$ under $\mathrm{N}_{2}$ saturated 
Table 1: Normalized amperometric responses of interfering species, as a percentage, at selected concentrations in $0.1 \mathrm{M} \mathbf{K C l}$. Applied potential is $+0.75 \mathrm{~V}$.

\begin{tabular}{lccc}
\hline & \multicolumn{3}{c}{ Concentration of species } \\
\cline { 2 - 4 } Interfering Species & $2.0 \times 10^{-6} \mathrm{M}$ & $7.4 \times 10^{-6} \mathrm{M}$ & $1.4 \times 10^{-5} \mathrm{M}$ \\
\hline Iodide ion (I-) & 25 & 33 & 40 \\
Manganese $\left(\mathrm{Mn}^{2+}\right)$ & 25 & 29 & 29 \\
Nitrite $\left(\mathrm{NO}_{2}^{-}\right)$ & 25 & 21 & 26 \\
Phenol & 25 & 25 & 26 \\
Sulfide $\left(\mathrm{S}^{2-}\right)$ & 25 & 21 & 26 \\
\hline
\end{tabular}

confirming the validity of the proposed amperometric detection method for Thiram with high accuracy.

Interferences: Among many species that are suspected to interfere with the electrochemistry of Thiram, as stated in the experimental section, only a few species (e.g., $\mathrm{Mn}^{2+}, \mathrm{NO}_{2}^{-}, \mathrm{S}^{2-}, \mathrm{I}^{-}$and phenol) resulted in considerable amperometric currents in the $\mathrm{KCl}$ medium. The normalized amperometric responses (ratio of the amperometric currents of the interferent and that of the analyte, Thiram) for each interferent at selected concentrations, and at $+0.75 \mathrm{~V}$ are shown in Table 1. It should be noted that the species not included in the table did not show any detectable response under the conditions employed for the detection of Thiram. As the electrochemistry of substances depends highly on the nature of the electrolyte medium, levels of interference was also investigated in acidic and basic media, in order to find a medium that shows the least interference.
Although only two species, $\mathrm{S}^{2-}$ and $\mathrm{I}$; interfered with Thiram in acidic medium $(\mathrm{pH}=1)$, their responses were very high when compared to that of Thiram, resulting in normalized currents of $100 \%$ and $118.5 \%$, respectively. Most importantly, no detectable interference was observed with any inorganic species investigated, when the solution $\mathrm{pH}$ was maintained at 10 , which was found to be the best $\mathrm{pH}$ according to cyclic voltammetric and amperometric investigation. Thus, the medium of $\mathrm{pH} 10$ for the detection of Thiram with high accuracy is further established.

This interference study demonstrates the applicability of electrochemical techniques in a real situation, where interference can be minimized, and hence selectivity can be greatly enhanced when experimental conditions are properly optimized. Hence, the need for an additional separation step, as in chromatographic detection, would not be crucial for a reliable result.

Table 2: Concentration of Thiram in water leached through soil at different time intervals.

\begin{tabular}{cccc}
\hline Time/h & $\begin{array}{c}\text { Concentration of } \\
\text { Thiram } \times 10^{6} / \mathrm{M}\end{array}$ & $\begin{array}{c}\text { Relative error } \\
(\%)\end{array}$ & $\begin{array}{c}\text { Confidence limits } \\
(95 \%)\end{array}$ \\
\hline 6 & $2.50+0.16$ & 6.4 & $2.50+0.11$ \\
12 & $2.22+0.17$ & 7.7 & $2.22+0.12$ \\
24 & $1.42+0.13$ & 9.2 & $1.42+0.13$ \\
36 & $1.17+0.10$ & 8.5 & $1.17+0.07$ \\
48 & $0.83+0.06$ & 7.2 & $0.83+0.04$ \\
72 & $0.80+0.07$ & 8.7 & $0.80+0.08$ \\
96 & $0.74+0.06$ & 8.0 & $0.74+0.08$ \\
\hline
\end{tabular}


Demonstration of the applicability of the method for real sample analysis

(A) Thiram in soil: The levels of Thiram present in the effluent water leached out from the laboratory prepared soil bed can be determined with adequate accuracy using the amperometric calibration curve shown in Figure 5. Table 2 shows the average concentrations of 20 replicate measurements of Thiram in lechates, determined after rejection of outlying results according to the Q-test at 95\% confidence level, at regular time intervals throughout a time period of $96 \mathrm{~h}$. The standard deviation associated with each measurement and the confidence limits at $95 \%$ confidence level are also listed in the Table. Low values of relative error $(6.4 \%$ to $9.2 \%)$ are indicative of the precision of the method developed. The concentration of Thiram in the leachate was determined to be $2.50 \times 10^{-3} \mathrm{M}$, six $\mathrm{h}$ after the application of a $2.90 \times 10^{-3} \mathrm{M}$ solution on soil. A decreasing pattern of Thiram concentration continued, as expected. The loss of concentration may be partly due to the degradation and adsorption of Thiram in soil.

(B) Thiram in seed sample: Amperometric analysis of the washings of bean seed samples, conducted in triplicate, under optimized conditions $(\mathrm{pH}=10,+0.50 \mathrm{~V})$, also resulted in reproducible current measurements. The average concentration of Thiram present in the seed sample was determined to be $0.47 \pm 0.08 \mathrm{~g} / \mathrm{kg}$, based on the amperometric calibration curve. The recommended dose of Thiram for bean seeds treatment is $1 \mathrm{~g} / \mathrm{kg} .{ }^{21}$ The result obtained is

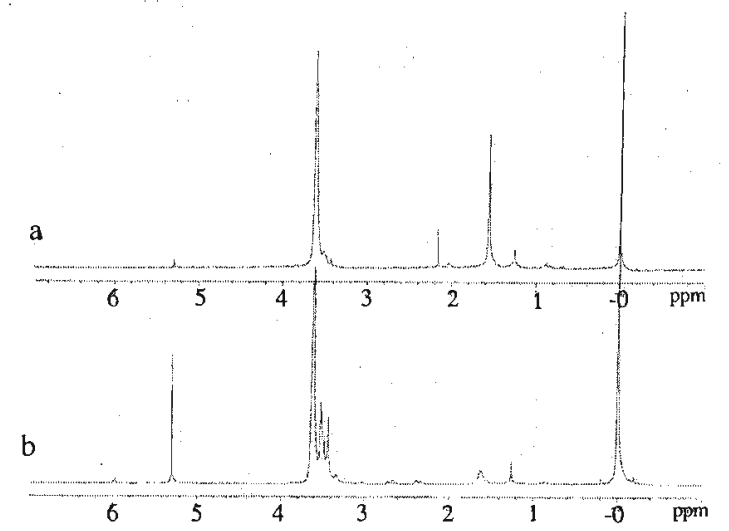

Figure 6: NMR spectra of (a) Commercial sample of Thiram (b) Residue of bean seed washings. somewhat less than expected. The seed sample may not have been exposed to the recommended dose, or alternatively, a fraction of Thiram may have been decomposed during a prolonged storage time.

Spectroscopic analysis: The presence of Thiram in the bean seed sample was independently confirmed by proton NMR and UV absorption spectroscopic methods. The $300 \mathrm{MHz}$ NMR spectra, taken for a sample of commercial Thiram and for the dried residue of the bean seed extract residue, in $\mathrm{CdCl}_{3}$, show an intense peak at a chemical shift of $3.6 \mathrm{ppm}$ due to methyl protons bound to nitrogen, suggesting that the bean seed sample contains Thiram (Figure 6). Other minor peaks could be due to possible additives in both types of samples.

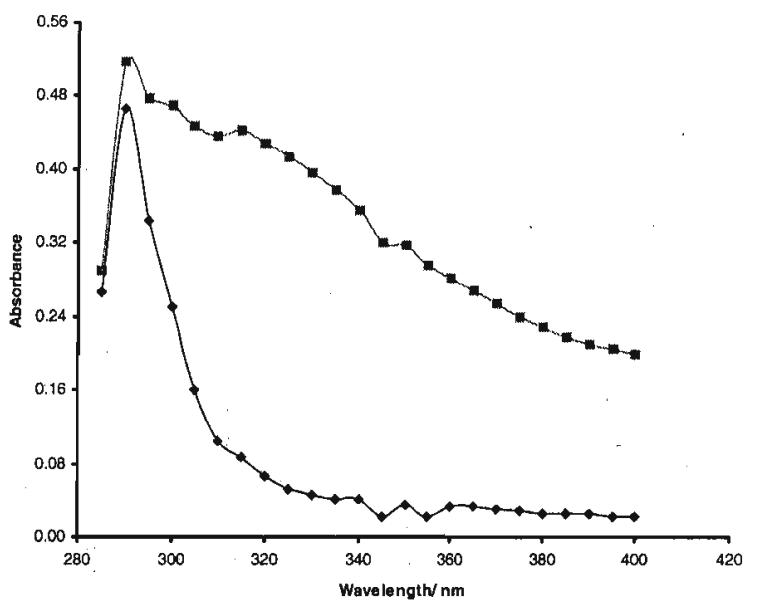

Figure 7: UV spectra.of a $5.0 \times 10^{-5} \mathrm{M}$ Thiram standard solution $(\downarrow)$ and the residue of bean seed washings $(\square)$.

Additionally, the UV-Visible spectra obtained for $5.0 \times 10^{-5} \mathrm{M}$ Thiram solution, prepared in $\mathrm{pH} 10$ borate buffer, and for a solution prepared using the extract of the bean seed sample in the same medium showed an absorption maximum at a wavelength of about $290 \mathrm{~nm}$ (Figure 7). These observations confirm the presence of Thiram in the bean seed sample.

Based on these findings, it can be concluded that the amperometric method developed is simple and sensitive. It can be used as a low-cost routine analytical tool for the analysis of environmental samples that are suspected to be polluted by Thiram. This amperometric method would have the potential 
to replace the traditional detection methods for Thiram.

\section{Acknowledgement}

The financial support from the National Science Foundation, Sri Lanka, for the grant No. 99/C/06 is gratefully acknowledged.

\section{References}

1. Vallack H.W., Bakker D.J., Brandt I., Broston- Lunden E., Brouwer A., Bull K.R., Gough C., Guadans R., Holubek I., Jansson B., Koch R., Kuylenstierna J., Leloux A., Mackray D., Mccutcheon P., Mocarelli P. \& Taalman R.D.F. (1998). Controlling persistant organic pollutants-what next? Environmental Toxicology and Pharmacology 6:143-175.

2. Amaraneni S.R. \& Pillala R.R. (2001). Concentrations of pesticide residues in tissues of fish from Kolleru Lake in India. Environmental Toxicology 16: 550- 556.

3. Hassal K.A. (1990). The Biochemistry and Uses of Pesticides: Structure, Metabolism, Mode of Action and Uses in Crop Protection. second edition, ELBS/ Macmillan Hampshire, pp 287.

4. Solanke R.B., Kore S.S. \& Sudewad S.M.J. (1997). Detection of soybean seed borne pathogens and effect of fungicides. Maharashtra Agricultural University 22: 168-170.

5. Raji P. \& Pillai M.V.R.. (1996). Effect of plant protection chemicals on Bradyrhizobium in cowpea. Journal of Tropical Agriculture 34: 125-128.

6. Dahlberg J.A., Peterson G.L., Odvody G.N. \& Bonde M. (1999). Inhibition of germination and sporulation of Claviceps africana from honeydew encrusted sorghum with seed treatment fungicides. Crop Protection 18: 235-238.

7. Ripley B.D., Lissemore L.I., Leishman P.D., Denomme M.A. \& Ritter L. (2000). Journal of AOAC International 83: 196-213.
8. Vryzas Z., Papadakis E.N. \& PapadopoulouMourkidou E. (2002). Microwave-assisted extraction (MAE)-acid hydrolysis of dithiocarbamates for trace analysis in tobacco and peaches. Journal of Agricultural Food Chemistry 50: 2220-2226.

9. British Crop Protection Council and Royal Society of Chemistry (1994). In: A world compendium Pesticide Manual: Incorporating the Agrochemical HandBook (Ed. Clieve Tomlin), tenth edition, Bath press, Bath, pp 989-990.

10. Cullen T.E. (1964). Spectrophotometric determination of dithiocarbamate residues on food crops. Analytical Chemistry 36(1): 221-224.

11. McLeod H.A. \& McCully K. A. (1969). Head space gas procedure for screening food samples for dithiocarbamate pesticide residues, Journal of the Association of Official Analytical Chemists 52: 1226- 1230.

12. De Silva M., Del P., Procopio J.R. \& Hernandez L. (1999). Electrochemical detection in the determination of several dithiocarbamates by reverse-phase liquid chromatography. Journal of Liquid Chromatography and Related Technologies 22: 463-475.

13. Mathieu C., Herbreteau B., Lafosse M., Renaud M., Cardinet C. \& Dreux M. (1999). Liquid chromatography and exchange reaction of a synthetic thiurams mixture Analytica Chimica Acta 402: 87.

14. Garrigues S., De la Guardia M., Cassella A.R., De Campos R.C., Santelli R.E. \& Cassella R.J. (2000). Flow injection-FTIR determination of dithiocarbamate pesticides. Analyst 125: 1829-1833.

15. Malik A.K. \& Faubel W. (2000). Capillary electrophoretic determination of tetramethylthiuram disulphide (Thiram). Analytical Letters 33: 2055-2064.

16. Gueguen F., Boisdde F., Queffelec A. L., Haelters J. P., Thouvenot D., Corbel B. \& 
Nodet P. (2000). Hapten synthesis for the development of a competitive inhibition enzyme-immunoassay for Thiram. Journal of Agricultral Food Chemistry 48: 4492-4499.

17. Mateos M.A., Galvez R., Manuel de Villena F.J. \& Pingarron J.M. (1995). Determination of propazine by differential pulse polarography in micellar and emulsified media. Mikrochimica Acta 120: 339-349.

18. Shaidarova L.G., Budnikov G.K. \& Zaripova S.A. (2001). Electrocatalytic determination of dithiocarbamate-based pesticides using electrodes modified with metal phthalocyanines. Journal of Analytical Chemistry 56: 748-753.
19. Hernandez-Olmos M.A., Agui L., YanezSedeno P. \& Pingarron J.M. (2000) Analytical voltammetry in lowpermittivity organic solvents using disk and cylindrical microelectrodes. Electrochimica Acta 46: 289-296.

20. Fernandez C.J., Reviejo A. J. \& Pingarron J. M. (1995). Development of graphitepoly(tetrafluoroethylene) composite electrodes: Voltammetric determination of the herbicides Thiram and Disulfiram. Analytica Chimica Acta 305: 192. 